\title{
POLA PERILAKU KOMUNIKASI MASYARAKAT DI KAWASAN ADAT AMMATOA KAJANG
}

\author{
Eva Rahmayani ${ }^{1}$, Muh Nadjib ${ }^{2}$, Kahar $^{3}$ \\ ${ }^{1}$ Fakultas Ilmu Sosial dan Ilmu Politik, Universitas Hasanuddin \\ email : evarahmayani1224@gmail.com \\ ${ }^{2}$ Fakultas Ilmu Sosial dan Ilmu Politik, Universitas Hasanuddin \\ email : nadjibnajib@yahoo.com \\ ${ }^{3}$ Fakultas Ilmu Sosial dan Ilmu Politik, Universitas Hasanuddin \\ email : kaharkom@gmail.com
}

\begin{abstract}
The research aims; (1) To know the pattern communication behavior of community in Ammatoa Kajang Costumary Area; (2) to find out the medium used by the community in Ammatoa Costumary Area in communicating. This research was taken place in Ammatoa costumary Area, Kajang. The informants of this research are costumary leaders, two costumary stakeholders and one of community of Ammatoa Kajang Costumary Area. The informants were selected using purposive sampling technique based on certain criteria. This type of research is descriptive qualitative. Primary data collected through observation and interviews, and secondary data collected through literature study related to the research. The results showed that the pattern of community in Ammatoa Kajang Costumary Area occurs verbally or nonverbally with others community and with god and nature. Verbal and nonverbal communication which occurs in community reflect how they are still very much preserving their customs with language, how to communicate, and symbols which they use, and their communication relationship with God and Nature. Medium of communication which they use also shows how they so appreciate their ancestors.
\end{abstract}

Keywords: Communication Behavior, Community, Ammatoa Costumary Area, Kajang

\begin{abstract}
ABSTRAK
Tujuan penelitian ini adalah; (1) untuk mengetahui Pola perilaku komunikasi masyarakat di Kawasan Adat Ammatoa Kajang; (2) untuk mengetahui sarana yang digunakan oleh masyarakat di Kawasan Adat Ammatoa dalam berkomunikasi. Penelitian ini dilaksanakan di Kawasan Adat Ammatoa, Kajang. Informan penelitian ini adalah pemimpin adat, dua pemangku adat dan salah satu masyarakat Kawasan Adat Ammatoa Kajang. Informan penelitian ditentukan secara purposive sampling berdasarkan kriteria-kriteria tertentu. Tipe penelitian ini bersifat deskriptif kualitatif. Data primer dikumpulkan melalui observasi dan wawancara, dan data sekundernya dikumpulkan melalui hasil studi pustaka yang terkait dengan penelitian. Hasil penelitian menunjukkan bahwa pola perilaku komunikasi masyarakat di Kawasan Adat Ammatoa Kajang terjadi secara verbal maupun nonverbal dengan sesama masyarakat serta dengan Tuhan dan alam. Komunikasi verbal maupun nonverbal yang terjadi dalam masyarakat mencerminkan bagaimana mereka masih sangat menjaga kelestarian adat mereka dengan bahasa, cara berkomunikasi dan simbol-simbol yang mereka gunakan, serta hubungan komunikasi mereka dengan Tuhan dan Alam. Sarana komunikasi yang mereka gunakan juga menunjukkan bagaimana mereka begitu menghargai leluhur mereka.
\end{abstract}

Kata Kunci: Perilaku Komunikasi, Masyarakat, Kawasan Adat Ammatoa, Kajang 


\section{PENDAHULUAN}

Komunikasi merupakan suatu hal yang sulit dipisahkan dari kehidupan manusia. Disadari atau tidak, manusia sebagai mahkluk sosial senantiasa tidak akan lepas dari suatu proses-proses komunikasi, baik secara verbal maupun non-verbal. Proses komunikasi tiap individu biasanya berbeda tergantung dimana orang tersebut berkomunikasi dan dengan siapa dia berkomunikasi. Karakter tersebut tentu memunculkan suatu pola perilaku komunikasi yang berbeda antara individu yang satu dengan individu lain maupun masyarakat satu dengan masyarakat lainnya. Perilaku komunikasi diartikan sebagai suatu tindakan komunikasi, yang meliputi tindakan verbal maupun tindakan non-verbal atau disebut perilaku komunikasi verbal dan perilaku komunikasi non-verbal.

Komunikasi dan budaya adalah dua hal yang tak dapat dipisahkan. Seperti dikemukakan oleh Deddy Mulyana dan Jalaluddin Rakhmat, dalam buku Komunikasi Antar Budaya (2005) sebagai berikut:

Budaya dan Komunikasi tak dapat dipisahkan oleh karena budaya tidak hanya menetukan siapa bicara dengan siapa, tentang apa dan bagaimana orang menyampaikan pesan, makna yang ia miliki untuk pesan, dan kondisi-kondisinya untuk mengirim, mem-perhatikan dan menafsirkan pesan.

Pernyataan di atas mengindikasikan bahwa salah satu hal yang juga dapat berpengaruh besar dalam pola perilaku komunikasi adalah budaya.

Budaya pada dasarnya merupakan nilai-nilai yang muncul dari proses interaksi antar individu. Nilai-nilai ini diakui, baik secara langsung maupun tidak langsung, seiring dengan waktu yang dilalui dalam interaksi tersebut. Bahkan terkadang sebuah nilai tersebut berlangsung di dalam alam bawah sadar individu dan diwariskan pada generasi berikutnya (Nasrullah, 2012).

Di zaman sekarang, tidak bisa kita pungkiri bahwa kehadiran globalisasi menjadi suau hal yang sulit untuk kita hindari. Hadirnya globalisasi menuntut kita untuk mengikuti segala hal yang sedang tren agar kita dianggap tidak ketinggalan zaman. Namun, di tengah gencarnya untuk mengaktualisasikan diri, kita juga dituntut untuk selalu sadar akan kekayaan budaya. Situasi ini tentu menjadi tantangan tersendiri di era globalisasi yang semakin hari semakin menunjukkan per-kembangan yang sangat signifikan.

Indonesia menjadi salah satu Negara yang mendapat pengaruh yang sangat besar dari hadirnya globalisasi. Indonesia terkenal sebagai Negara yang kaya akan kebudayaan, namun tidak bisa dipungkiri bahwa kehadiran globalisasi telah membuat keberagaman seperti hilang dalam diri bangsa Indonesia. Kebiasaan, adat istiadat, pola hidup dan cara pandang masyarakat terhadap suatu yang dulunya beragam kini terlihat hampir sama di setiap budaya yang ada di Indonesia. Dengan kata lain, kehadiran globalisasi telah mengubah sebagian besar penduduk Indonesia yang dulunya menganut budaya yang berbeda sesuai dengan daerahnya kini menganut satu budaya yang sama yang dikenal dengan budaya modern.

Disaat perkembangan globalisasi di Indonesia berhasil mengubah sebagian besar kebudayan tradisional Indonesia menjadi kebudayaan modern, masih ada beberapa wilayah yang tetap mem-pertahankan kebudayaan lokal mereka. Salah satu wilayah di Indonesia dengan integritas kebudayaan yang sangat tinggi dan dianggap cukup berhasil 'melawan' era globalisasi dengan tetap mempertahankan budaya lokal di tengah maraknya budaya modern yang masuk di Indonesia adalah masyarakat Kajang, khususnya yang bermukim dalam Kawasan Adat Ammatoa Kajang, yang berada di Provinsi Sulawesi Selatan, tepatnya di Kabupaten Bulukumba. Masyarakat ini merupakan salah satu fenomena sosial yang khas dan unik yang memberikan tatanan kehidupan yang berbeda dengan kebudayaan lainnya.

Masyarakat Kajang terbagi dalam dua kawasan, yaitu masyarakat Kajang Luar dan Masyarakat Kajang Dalam. Masyarakat Kajang Luar menempati wilayah di luar kawasan adat Ammatoa sedangkan masyarakat Kajang Dalam menempati wilayah di dalam kawasan Adat Ammatoa. Kawasan Adat Ammatoa ini berada di Desa Tana Towa, Kecamatan Kajang Kabupaten Bulukumba.

Masyarakat yang bermukim di luar Kawasan Adat Ammatoa sedikit demi sedikit mulai mengadaptasi kebudayaan lain dalam 
pola hidup mereka, sehingga nilai-nilai budaya khas masyarakat di luar kawasan Adat Ammatoa yang dianut tidak sekuat dengan masyarakat yang bermukim di dalam Kawasan adat Ammatoa. Sedangkan Masyarakat yang tinggal dalam Kawasan Adat Ammatoa masih sepenuhnya berpegang teguh kepada adat Ammatoa.

Dalam Kawasan Adat Ammatoa Kajang dikenal suatu komunitas yang menamakan diri mereka Komunitas Ammatoa. mereka dipimpin oleh seorang pemimpin adat yang dikenal dengan sebutan Ammatoa. Dalam struktur kelembagaan adat, Komunitas Ammatoa ini terdiri atas 25 pemangku adat yang memiliki tugas masing-masing untuk membantu Ammatoa dalam menjalankan struktur kelembagaan adat.

Perbedaan posisi dan tugas dalam struktur kelembagaan adat masyarakat di Kawasan Adat Ammatoa Kajang ini membuat pola perilaku komunikasi mereka tentu berbeda dengan masyarakat di daerah lain. Ada saat-saat tertentu dimana masyarakat hanya bisa berkomunikasi dengan pemimpin adatnya melalui pemangku adat, ada juga waktu dimana masyarakat juga bisa berkomunikasi langsung dengan Ammatoa dan juga ada saat dimana pemimpin adat menjalankan tugasnya sebagai pemimpin untuk mengatur komunikasi antara pemangku adat dengan masyarakat. Selain berkomunikasi dengan sesama masyarakat di Kawasan Adat Ammatoa, mereka juga percaya bahwa mereka melakukan komunikasi dengan Tuhan dan alam. Sarana komunikasi yang mereka gunakan juga tentu berbeda dengan masyarakat di daerah lain. Hal ini tidak terlepas dari cara hidup mereka yang masih sangat sederhana dengan sepenuhnya berpegang teguh pada adat istiadat yang telah turun temurun. Mereka menolak masuknya teknologi dalam wilayah mereka karena mereka menganggap bahwa kehadiran teknologi dapat membawa dampak negatif bagi kehidupan mereka, karena bersifat merusak kelestarian alam.

\section{KAJIAN LITERATUR DAN PENGEMBANGAN HIPOTESIS}

Perilaku komunikasi adalah suatu aktifitas atau tindakan manusia dari proses adanya stimulus terhadap organisme, dan kemudian organisme tersebut merespons. Sehingga dapat disimpulkan bahwa komunikasi akan berlangsung dengan baik dan berhasil apa bila ada kesamaan makna antara komunikator dan komunikan, baik secara verbal (bahasa) maupun secara nonverbal (simbol atau gerak tubuh).

Komunikasi verbal adalah komunikasi yang menggunakan kata-kata, baik lisan maupun tulisan. Komunikasi ini paling banyak dipakai dalam hubungan antarmanusia. Melalui kata-kata, mereka mengungkapkan perasaan, emosi, pikiran, gagasan, atau maksud mereka menyampaikan fakta, data dan informasi serta menjelaskannya, saling bertukar perasaan dan pemikiran, saling berdebat dan bertengkar. Dalam komunikasi verbal, bahasa memegang peranan penting, karena bahasa mampu menerjemahkan pikiran seseorang kepada orang lain.

Komunikasi verbal ditandai dengan ciri-ciri, yakni disampaikan secara lisan atau tulisan dan proses komunikasi cenderung dua arah. Adapun jenis dalam komunikasi verbal yakni; Berbicara dan Menulis. Berbicara adalah komunikasi verbal-vokal, contohnya presentasi dalam rapat. Sedangkan tertulis adalah komunikasi verbal-nonvokal, contohnya surat menyurat; Mendengarkan dan Membaca. Mendengarkan berarti mengambil makna dari apa yang didengar, melibatkan 4 unsur yaitu mendengar, memperhatikan, memahami dan mengingat. Membaca adalah suatu cara untuk mendapat informasi dari sesuatu yang ditulis.

Komunikasi nonverbal adalah proses komunikasi dimana pesan disampaikan tidak menggunakan kata-kata. Dengan komunikasi nonverbal orang dapat mengekspresikan perasaannya melalui bahasa tubuh, gerak isyarat, ekspresi wajah, kontak mata, penggunaan objek seperti pakaian, simbolsimbol serta cara berbicara seperti intonasi, penekanan, kualitas suara, gaya emosi, dan gaya berbicara.

Adapaun bentuk dan tipe umum dari komunikasi nonverbal menurut Bellak dan Baker (1981) dalam (Liliweri (1994 : 143) ada tiga, yakni : Kontak mata, mengacu pada sesuatu yang disebut Gaze yang meliputi suatu keadaan penglihatan secara langsung antarorang disaat berbicara. Kontak mata sangat menentukan kebutuhan psikologis dan membantu kita memantau efek komunikasi antapribadi; Ekspresi wajah, meliputi pengaruh raut wajah yang dipergunakan untuk 
berkomunikasi secara emosional atau bereaksi terhadap suatu pesan; Gesture atau gerakan tubuh, merupakan bentuk perilaku nonverbal pada gerakan tangan, bahu, jari-jari dan kaki. Orang sering menggunakan gerakan anggota tubuh secara sadar maupun tidak sadar untuk menyampaikan suatu pesan.

Perilaku manusia dalam kehidupannya dipengaruhi oleh banyak faktor yang melatarbelakangi dalam berperilaku, diantaranya perilaku dipengaruhi oleh sikap dan lingkungan sebagai respon terhadap suatu kondisi. Selanjutnya perilaku dibagi atas dua.

Pertama, perilaku sebagai upaya memenuhi kepentingan atau guna mencapai sasararan adalah perilaku yang terbentuk oleh gerak dari dalam dan berjalan secara sadar. Yang dimaksud dengan penggerak dari dalam adalah sistem nilai yang ditambahkan atau tertanam, melembaga dan hidup didalam diri orang yang bersangkutan. Nilai tertanam dan berarti nilai menjadi keyakinan, pendirian atau pegangan. Perilaku merupakan aktualisasi, sosialisasi dan internalisasi keyakinan, pendiri atau sikap.

Kedua, perilaku sebagai respon terhadap lingkungan merupakan respon terhadap treatment dari atau kondisi lingkungan. Dan pembentukan perilaku dari luar itu ada yang berupa stimulus berdasarkan stimulus respon (seperti pujian, hadiah atau berupa teguran) dan ada yang berwujud challenge berdasarkan challenge respon yang berupa tanggung jawab, persaingan, perlombaan, kemenangan, kejuaraan, kehormatan dan sebagainya.

Media komunikasi adalah seluruh alat atau sarana yang digunakan untuk menyalurkan atau menyebarkan dan juga menyajikan informasi. Berdasarkan jangkauannya, media komunikasi dibagi menjadi dua. Pertama, media komunikasi eksternal, merupakan suatu media komunikasi yang dipakai untuk menjalin hubungan dan menyampaikan pesan informasi dengan pihak-pihak luar, misalnya: Media komunikasi tertulis/cetak, radio, televisi/TV, telepon, telepon selular (Handphone), surat dan internet. Sedangkan media komunikasi internal ialah seluruh sarana penyampaian dan penerimaan pesan informasi dikalangan publik internal, dan pada umumnya mempunyai sifat non-komersial. Media yang bisa dipakai sebagai komunikasi internal yaitu, seperti: surat. Telephone, papan pengumuman, majalah bulanan, media pertemuan dan pembicaraan, dll.

\section{METODE PENELITIAN}

Penelitian ini dilakukan selama 2 bulan yaitu mulai bulan Februari sampai dengan bulan April 2017 di Kawasan Adat, Desa Tana Towa, Kecamatan Kajang, Kabupaten Bulukumba, Sulawesi Selatan.

Pengumpulan data dilakukan untuk memperoleh data yang berkaitan dengan penelitian. Data yang digunakan adalah data primer dan data sekunder. Data primer merupakan data yang secara langsung diperoleh dari sumbernya melalui wawancara dan observasi. Data skunder diperoleh melalui studi kepustakaan untuk memperoleh data dari beberapa literatur yang relevan dan erat kaitannya dengan permasalahan yang dibahas. Dilakukan dengan membaca sejumlah buku, hasil penelitian, jurnal, situs internet dan bahan kuliah yang ada relevansinya dengan masalah yang akan diteliti.

Tipe penelitian menggunakan metode kualitatif. Adapun jenis penelitian yang digunakan adalah penelitian deskriptif kualitatif dengan menggunakan pendekatan etnografi.

Teknik pemilihan informan yang digunakan dalam penelitian ini adalah teknik purposive sampling, yakni memilih informan berdasarkan kriteri tertentu. Adapun informan dari penelitian berjumlah empat orang, yakni : Pak Salam, Kepala Desa Tana Towa yang juga menjabat sebagai Pemangku Adat yang bergelar Galla Lombo dalam struktur kelembagaan adat Ammatoa Kajang; Ammatoa, merupakan pemimpin adat, menempati posisi tertinggi dalam struktur kelembagaan adat Ammatoa Kajang; Pak Andi Asis, pemimpin adat yang bergelar Galla Puto dalam struktur kelembagaan adat Ammatoa Kajang, beliau adalah juru bicara Ammatoa; Pak Herman, salah satu masyarakat yang tinggal di Kawasan Adat Ammatoa Kajang.

Peneliti menggunakan teknik analisis data berdasarkan model Miles dan Hubberman untuk melakukan interpretasi data. Teknik analisis ini terdiri dari tiga alur kegiatan, yaitu; reduksi data, merangkum hal-hal pokok dan memfokuskan pada hal-hal penting; penyajian 
data, mendeskripsikan sekumpulan data yang teah diperoleh; dan penarikan kesimpulan.

\section{HASIL DAN PEMBAHASAN}

\section{HASIL PENELITIAN}

\section{Perilaku komunikasi masyarakat di Kawasan Adat Ammatoa Kajang, baik secara verbal maupun nonverbal}

Pasang ri Kajang merupakan bentuk komunikasi verbal masyarakat di Kawasan Adat Ammatoa Kajang yang menjadi Pedoman Hidup Masyarakat di Kawasan Adat Ammatoa Kajang. Secara harfiah, Pasang berarti "Pesan". Akan tetapi dalam pengertian komunitas Ammatoa, Pasang mengandung makna yang lebih dari sekedar pesan. Pasang $r i$ Kajang merupakan pedoman hidup masyarakat Ammatoa yang terdiri dari kumpulan amanat leluhur. Nilai-nilai yang terkandung dalam Pasang dianggap sakral oleh masyarakat Ammatoa. Terbukti bahwa Pasang merupakan sesuatu yang wajib hukumya untuk dituruti, dipatuhi dan dilaksanakan, yang bila tidak dilaksanakan, akan berakibat munculnya halhal yang tidak diinginkan seperti rusaknya keseimbangan sistem sosial dan ekologis, antara lain berwujud penyakit tertentu (Natabai Passau) pada yang bersangkutan maupun terhadap keseluruhan warga. Begitulah keyakinan masyarakat Ammatoa terhadap Pasang ri Kajang.

Pasang memuat berbagai ajaran leluhur yang substansinya adalah menuntun manusia untuk berbuat baik, hidup jujur dan sederhana. Pasang mengajarkan bahwa hidup yang cukup itu adalah bila makanan ada, pakaian ada, pembeli lauk ada, sawah dan ladang ada dan rumah yang sederhana saja".

Dengan didasari Pasang Ri Kajang, maka terbentuklah aturan-aturan adat yang berlaku dan harus dipatuhi. Karena itu, bagi yang melanggar aturan adat, diberi sanksi oleh Pemimipin Adat (Ammatoa). Namun, sanksi-sanksi yang diberikan oleh Ammatoa memilki takaran-takaran sanksi tersendiri.

Secara umum, ada hal yang menjadi pokok aturan di dalam adat Ammatoa yaitu sebagai berikut :
1) Melaksanakan perintah adat dan menjauhi hal-hal yang dilarang.

2) Patuh dan taat pada aturan-aturan adat.

3) Menghargai dan menghormati aturan adat.

Pokok aturan tersebut merupakan landasan dalam menjalankan aturan-aturan adat di Kawasan Adat Ammatoa yang berlaku untuk semua. Maksudnya, bahwa siapa pun itu tanpa pandang bulu, tanpa melihat pangkat, derajat, harkat dan martabat seseorang, kalau melanggar aturan berarti harus dihukum sesuai dengan hukum adat yang berlaku. Ditekankan pula bahwa sesuatu yang sakral itu tidak boleh di-pertanyakan "kenapa tidak boleh" karena sudah menjadi ketentuan adat. Bagi orang yang membuat pelanggaran, akan berakibat fatal bagi dirinya sendiri. Dan sebaliknya, jika menaati aturan adat maka orang tersebut dijuluki orang yang selamat.

Selain Pasang, komunikasi verbal masyarakat di Kawasan adat Ammatoa juga dapat dilihat dari berbagai situasi berikut:

a. Mereka berkomunikasi satu sama lain ketika mereka bertemu di jalan (saling menyapa), menghadiri acara adat (berbincang-bincang), sebelum melakukan ritual adat (melakukan pembagian tugas untuk menyiapkan hal-hal yang dibutuhkan untuk ritual).

b. Ketika terjadi pelanggaran adat atau kasus kejahatan di Kawasan Adat, semua berkumpul di rumah Ammatoa untuk melakukan proses peradilan. Ammatoa menjadi hakim/pemimpin sidang. Pemangku adat dan masyarakat hanya bisa saling berkomunikasi melalui Ammatoa.

c. Pemangku adat menjadi penghubung antara Ammatoa dan Masyarakat dalam berkomunikasi ketika: (1) Ada masyarakat yang diutus ke luar daerah untuk melakukan pertemuan atau mengikuti kegiatan. Pemangku Adat harus berbicara terlebih dahulu dengan masyarakat yang diutus tersebut kemudian menyampaikan kepada Ammatoa. Jika sudah ada persetujuan dari Ammatoa, barulah orang tersebut bisa diutus ke luar daerah; (2) ketika ada masyarakat yang membutuhkan kayu di hutan yang ada di Kawasan Adat Ammatoa, yang bersangkutan harus menyampaikan ke pemangku adat yang 
telah ditugaskan. Pemangku adat inilah yang menyampaikan ke Ammatoa untuk meminta persetujuan. Jika sudah ada izin dari Ammatoa, pemangku adat kemudian memeriksa persediaan kayu. Jika ada kayu yang tersedia, masyarakat tersebut diizinkan mengambil kayu setelah memenuhi syarat yang telah diatur dalam aturan adat.

d. Selain berkomunikasi dengan sesama masyarakat, masyarakat di Kawasan Adat juga berkomunikasi dengan Tuhan dan Alam. Komunikasi dengan Tuhan dilakukan dengan melaksanakan ritualritual adat. Komunikasi dengan alam bisa dilihat dari keseharian mereka yang tidak memakai sandal dan juga cara mereka mengelola hutan (komunikasi nonverbal)

\section{Sarana yang digunakan masyarakat di Kawasan Adat dalam Berkomunikasi}

Masyarakat di kawasan adat Ammatoa dikenal sebagai masyarakat yang menolak masuknya teknologi ke wilayah mereka karena mereka menganggap bahwa dengan masuknya teknologi maka akan merusak keseimbangan ekosistem alam. Meskipun ada beberapa masyarakat yang sudah memiliki handphone (HP), namun mereka hanya menggunakan HP tersebut ketika berada di luar kawasan adat. mereka menitipkan HP mereka di rumah keluarga yang tinggal di luar kawasan adat atau jika mereka memasukkan HP tersebut ke dalam kawasan, maka HP tersebut dimatikan. Hal ini juga meraka lakukan untuk mengikuti aturan dalam Pasang yang mengajarkan tentang kesedarhanaan dan juga mematuhi aturan adat yang berlaku dalam kawasan tempat tinggal mereka.

Mereka menggunakan sarana komunikasi tatap muka dalam berkomunikasi, yakni musyawarah, rapat dan gotong royong. Rapat dan musyawarah biasanya dilakukan oleh Pemimpin adat dan pemangku adat. Dalam rapat, pemangku adat memiliki hak untuk memberikan saran kepada Ammatoa dalam menjalankan struktur roda pemerintahan adat. Rapat ini juga menjadi wadah bagi Ammatoa untuk mengevaluasi kinerja pemangku adat. Musyawarah dilakukan untuk membahas Pasang (pedoman hidup masyarakat di Kawasan Adat Ammatoa), hal-hal yang harus diubah dan hal-hal yang tetap dipertahankan.
Gotong royong dilakukan ketika mereka akan melakukan ritual adat, mereka bekerjasama untuk menyiapkan hal-hal yang dibutuhkan untuk ritual.

Adapun sarana yang mereka gunakan untuk berkomunikasi dengan Tuhan dan Alam adalah biji jagung, ayam putih dan padupaan (dalam proses pemilihan pemimpin adat), dan linggis (untuk mengetahui pelaku kejahatan dan menghukum pelaku kejahatan tersebut).

\section{PEMBAHASAN}

\section{POLA PERILAKU KOMUNIKASI MASYARAKAT DI KAWASAN ADAT AMMATOA KAJANG}

Perilaku manusia dalam kehidupannya dipengaruhi oleh banyak faktor yang melatarbelakangi dalam berperilaku, diantaranya perilaku dipengaruhi oleh sikap dan lingkungan sebagai respon terhadap suatu kondisi.

Perilaku dibagi atas dua. Pertama, perilaku sebagai upaya memenuhi kepentingan atau guna mencapai sasararan, adalah perilaku yang terbentuk oleh gerak dari dalam dan berjalan secara sadar. Yang dimaksud dengan penggerak dari dalam adalah sistem nilai yang ditambahkan atau tertanam, melembaga dan hidup didalam diri orang yang bersangkutan. Nilai tertanam dan berarti nilai menjadi keyakinan, pendirian atau pegangan. Perilaku merupakan aktualisasi, sosialisasi dan internalisasi keyakinan, pendiri atau sikap. Kedua, perilaku sebagai respon terhadap treatment dari kondisi lingkungan. pembentukan perilaku dari luar itu ada yang berupa stimulus berdasarkan stimulus respon, seperti pujian, hadiah atau berupa teguran, dan ada yang berwujud challenge berdasarkan challenge respon yang berupa tanggung jawab, persaingan, perlombaan, kemenangan, kejuaraan, kehormatan dan sebagainya.

Perilaku komunikasi masyarakat di Kawasan Adat Ammatoa Kajangterbentuk oleh gerak dari dalam dan berjalan secara sadar, yaitu sistem nilai yang telah tertanam, melembaga dan hidup didalam diri mereka. Nilai tertanam berarti nilai yang menjadi keyakinan, pendirian atau pegangan mereka, dalam hal ini adalah Pasang ri Kajang. 
Perilaku merupakan aktualisasi, sosialisasi dan internalisasi keyakinan, pendiri atau sikap. Hal ini bisa dilihat dari sikap mereka yang masih tetap mempertahankan adat istiadat mereka di saat globalisasi semakin hari semakin berkembang dengan pesat.

Perilaku komunikasi adalah tindakan dalam berkomunikasi yang terjadi secara berulang, meliputi tindakan verbal maupun nonverbal. Masyarakat di Kawasan Adat Ammatoa Kajang melakukan komunikasi secara verbal dengan sesama masyarakat dan juga dengan Tuhan dan Alam.

\section{Perilaku Komunikasi Verbal}

Komunikasi verbal adalah medium yang paling cepat untuk menyatakan pikiran dan perasaan yang dikeluarkan baik secara lisan maupun tertulis. Proses komunikasi dalam komunikasi verbal cenderung dua arah.

Komunikasi verbal antara sesama masyarakat di Kawasan Adat Ammatoa Kajang (pemimpin adat, pemangku adat, dan masyarakat) terjadi ketika mereka bertemu di jalan, mereka saling menyapa satu sama lain atau mereka berbincang-bincang. Perbincangan juga terjadi ketika mereka bertemu di acaraacara adat. Dalam komunikasi verbal, hal yang utama adalah bahasa yang digunakan. Masyarakat di Kawasan Adat Ammatoa Kajang meng-gunakan bahasa yang sama ketika mereka berkomunikasi satu sama lain, yakni bahasa Konjo. Bahasa tersebut menjadi bahasa yang diketahui oleh seluruh masyarakat di Kawasan Adat Ammatoa dan menjadi bahasa sehari-hari mereka.

Komunikasi verbal masyarakat dengan Tuhan dan Alam dilakukan dengan cara berdoa ketika melakukan ritual-ritual adat. Ritual adat yang dimaksud adalah;

a) A'nganro, adalah sebuah ritual adat tertinggi secara umum dalam masyarakat di Kawasan Adat Ammatoa Kajang, dimana acara tersebut merupakan tuntunan dan selamatan hajat terhadap keberadaan dunia(lino) akhirat (Ahere) semoga selalu dalam lindungan Tuhan Yang Maha Berkehendak.

b) Andingingi, adalah acara ritual tahunan masyarakat di Kawasan Adat Ammatoa Kajang, dimana acara tersebut merupakan rasa syukur dari segala nikmat yang diberikan kepada kita semua semoga tetap mendapat rezki yang halal dalam keadaan aman, damai serta terhindar dari segala bencana dan malapetaka.

c) Appasono', adalah suatu acara ritual yang sewaktu-waktu dilakukan apabila tanaman, baik pertanian maupun perkebunan warga terganggu oleh hama tikus.

Dalam melakukan ritual mereka juga menggunakan bahasa yang mereka gunakan sehari-hari ketika berkomunikasi dengan sesama masyarakat, yakni bahasa Konjo.

\section{Perilaku Komunikasi Nonverbal}

Bentuk komunikasi nonverbal itu seperti bahasa isyarat, ekspresi wajah, sandi, simbol-simbol, pakaian seragam, warna dan intonasi suara.

Masyarakat di Kawasan Adat Ammatoa Kajang menggunakan simbol-simbol berikut sebagai bentuk komunikasi nonverbal mereka ;

Pertama, mereka menggunakan baju yang berwarna hitam atau gelap. Hitam merupakan sebuah warna adat yang kental akan kesakralan dan bila kita memasuki kawasan ammatoa pakaian kita harus berwarna hitam. Warna hitam mempunyai makna bagi Mayarakat Ammatoa sebagai bentuk persamaan dalam segala hal, ter-masuk kesamaan dalam ke-sederhanaan. tidak ada warna hitam yang lebih baik antara yang satu dengan yang lainnya. Semua hitam adalah sama.

Kedua, kesehariaan mereka yang tidak menggunakan alas kaki. Mereka percaya bahwa tanah adalah tempat mereka diciptakan sehingga mereka tidak meng-gunakan alas kaki agar kulit mereka bersentuhan langsung dengan tanah, tempat dimana mereka berawal dan berakhir.

Ketiga, masyarakat di Kawasan Adat Ammatoa Kajang menganggap hutan sebagai sumber kehidupan mereka. Mereka sangat menjaga kelestarian hutan dengan tidak menebang secara sem-barangan, karena mereka percaya bahwa hutan di kawasan adat memiliki kekuatan gaib. Hutan dikelola berdasarkan adat istiadat dan dikelola secara sungguh-sungguh, karena mereka meng-anggap bahwa mengelola hutan sama saja menyayangi dunia. 
Keempat, Semua rumah warga dibangun dari bahan yang sama. Bangunan rumahnya terbuat dari kayu. Sementara atapnya terbuat dari ijuk. Tidak hanya bahan, bentuk rumahnya juga sama. Bahkan model dalam rumah pun sama. Rumah adat Kajang tidak seperti rumah pada umumnya, karena saat masuk pertama kali, yang dijumpai adalah dapur, kemudian ruang tamu. Rumah- rumah tersebut antara dapur dan ruang tamunya tidak bersekat. Ini juga merupakan simbol penghormatan dan keterbukaan pada tamu, yang berarti apapun yang dimakan oleh sang empunya rumah, maka tamu juga berhak memakannya. Dapur mereka be-rada di depan karena mereka meng-anggap dapur merupakan tempat yang selalu kotor, dan menganggap dapur adalah bagian kaki. Konon, konsep ini tidak hanya menunjukkan kesederhanaan, mereka juga menganggapnya sebagai simbol keseragaman. Mereka percaya, jika ada keseragaman tidak akan ada rasa iri di antara masyarakat suku Kajang.

\section{KESIMPULAN}

a. Pola perilaku komunikasi masyarakat di Kawasan Adat Ammatoa, baik secara verbal maupun nonverbal terjadi ketika mereka berkomunikasi dengan sesama masyarakat serta dengan Tuhan dan Alam. (1) Perilaku komunikasi verbal dengan sesama masyarakat terjadi ketika ada acara adat, sebelum melakukan ritual, ketika Ammatoa dan Pemangku Adat melakukan rapat, ketika terjadi proses peradilan di rumah Ammatoa karena ada pelanggaran dalam kawasan, ketika ada masyarakat yang diutus untuk melakukan pertemuan atau mengikuti kegiatan di luar kawasan dan ketika ada masyarakat yang membutuhkan kayu di hutan yang ada di kawasan. Sedangkan perilaku komunikasi verbal dengan Tuhan dan alam terjadi pada saat mereka melakukan ritual-ritual adat mereka. (2) Bentuk perilaku komunikasi nonverbal masyarakat di Kawasan Adat Ammatoa dapat dilihat dari: Pertama, mereka menggunakan baju yang berwarna hitam atau gelap; Kedua, kesehariaan mereka yang tidak menggunakan alas kaki; Ketiga, masyarakat di Kawasan Adat Ammatoa Kajang juga sangat menjaga kelestarian hutan dengan tidak menebang secara sembarangan; Keempat, Semua rumah warga dibangun dari bahan yang sama. Tidak hanya bahan, bentuk rumahnya juga sama. Bahkan model dalam rumah pun sama.

b. Ada beberapa sarana komunikasi yang digunakan oleh masyarakat di Kawasan Adat Ammatoa dalam berkomunikasi: yakni musyawarah dan gotong royong; Pasang sebagai sarana untuk mengingatkan tentang kehidupan masyarakat yang sesuai dengan adat-istiadat; biji jagung, ayam putih, dan pedupaan sebagai sarana dalam pemilihan pemimpin adat (Ammatoa); dan linggis (Tunu Panroli) sebagai sarana untuk mencari dan menghakimi pelaku kejahatan.

\section{DAFTAR PUSTAKA}

Abdullah, Ahmad M, dkk. 2014.'Ammatoa: Komunitas Tradisional Kajang di Tengah Transformasi Komunikasi dan Informasi'. Jurnal Komunikasi KAREBA. Vol. 3, No. 2

Effendy, Onong Uchjana. 2005. Ilmu Komunikasi Teori dan Praktek. Bandung: PT. Remaja Rosdakarya.

Hijjang, Pawennari. 2005. 'Pasang dan Kepemimpinan Ammatoa: Memahami Kembali Sistem Kepemimpinan Tradisional Masyarakat Adat dalam Pengelolaan Sumberdaya Hutan di Kajang Sulawesi Selatan'. Jurnal Antropologi Indonesia. Vol. 29 No.3.

Kriyantono, Rachmat. 2014. Riset Komunikasi. Jakarta: Kencana.

Liliweri, Alo. 1994. Komunikasi Verbal dan Nonverbal. Bandung: PT Citra Aditya Bakti.

Mulyana, Deddy. 2005. Ilmu Komunikasi Suatu Pengantar. Bandung: PT Remaja Rosdakarya.

\& Jalaluddin Rahmat. 1993. Komunikasi Antar Budaya. Bandung: PT Remaja Rosdakarya. 
Nasrullah, R. 2012. Komunikasi AntarBudaya Di Era Budaya Siber. Jakarta: Kencana.

Sugiyono. 2009. Metode Penelitian Kuantitatif, Kualitatif dan $R \& D$. Bandung: Alfabeta.

Syarifuddin. 2014. 'Komunikasi Pemerintah dan Masyarakat Berbasis Dialek Budaya Lokal (Studi Kasus Proses Komunikasi Penunjang Pembangunan Berbasis Dialek Konjo pada Masyarakat di Tana Toa Kajang Kabupaten Bulukumba'. Jurnal Studi Komunikasi dan Media. Vol. 18 No. 2:247-257. 